\title{
PRÓlOGO, POSFÁCIO E NOTAS: O PROJETO NACIONAL EM IRACEMA
}

Maria Cecília Boechat

Universidade Federal de Minas Gerais

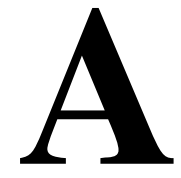

o Ceará natal, José de Alencar dedica Iracema, "este livrinho" que chega, "da corte imprevisto", ao Doutor prólogo à primeira edição, "para ser lido lá, na varanda da casa rústica ou na fresca sombra do pomar (...)". Daí que, sejam quais forem a hora ou lugar, essa chegada sempre se dará "à hora mais ardente da sesta", quando a dona da casa "manda abrir o coco verde, ou prepara o saboroso creme do buriti para refrigerar o esposo, que pouco há recolheu de sua excursão pelo sítio", encontrando-o, portanto, "já se embalando na macia e cômoda rede".

Livrinho para ser lido na rede, a ele se atribui uma função muito clara: "Percorra suas páginas para desenfastiar o espírito das cousas graves que o trazem ocupado", aconselha o autor. ${ }^{1}$ No entanto, o texto, prolixo, "inchado", de início impõe resistência ao acompanhamento desse convidativo enredo amoroso urdido no entrecho histórico, uma vez que marcado pela profusão não apenas de comparações, metáforas e descrições, como também de notas explicativas.

Essa profusão já foi ressaltada por Silviano Santiago - em sua edição comentada de Iracema -, sendo interpretada em termos de uma tentativa de controle autoral:

${ }^{1}$ ALENCAR, José de. Prólogo (da 1a. edição de Iracema) In: Obra completa. Vol. I. Rio de Janeiro: Aguilar, 1959. p.234. 
Esse cuidado extremo pela sorte do texto (...) redunda numa característica excepcional de Alencar: é o escritor brasileiro onde fica mais claro o desejo de sempre cercar, cercear, o caminho livre do texto, precedendo-o e seguindo-o de prefácios e posfácios, bem como protegendo-o com notas explicativas. ${ }^{2}$

Não deixa de ser significativo lembrar que, sendo uma edição comentada, a análise crítica apresenta-se justamente na forma de notas e que, ao lançar mão de uma das estratégias da própria narrativa, o editor tenha deslocado as notas do autor para o fim do texto. Nessa perspectiva, o raciocínio parece paradoxal: as notas do editor, que sem dúvida se querem crítico-reflexivas, ou, em outras palavras, doadoras de uma liberdade de interpretação que teria sido cerceada pelas notas autorais, ocupam justamente o lugar antes atribuído ao cerco, não reconhecendo-se, nestas, a função que se afirma naquelas. Para não recair no paradoxo, forçoso é, então, estabelecer as possíveis funções da nota, ou, mais especificamente, de suas funções na leitura de Iracema.

Rápido passar d'olhos no conjunto de notas do romance perceberá que a maioria delas esclarece questões lingüísticas, compondo um vocabulário que, explicando o significado de termos do tupi guarani ou o processo de criação de neologismos, vem responder à opacidade enfrentada pela leitura do texto. Cabe, assim, ao rodapé, promover uma espécie de "refamiliarização" lingüística e ser, ao mesmo tempo, espaço de encenação de um desconfortável estranhamento frente a uma linguagem que esperávamos conhecida, familiar, porque genuinamente nossa, "brasileira". Expectativa que é, afinal, legítima, uma vez que, além de hoje encontrarmos consolidada, na tradição crítico-historiográfica, a pertinência de Iracema a um projeto de construção de um romance e de uma linguagem nacionais, o leitor contemporâneo do autor já encontrava,

${ }^{2}$ In: ALENCAR, José de. Iracema. Notas e orientação didática por Silviano Santiago. Rio de Janeiro: Francisco Alves, 1975. [Romance para estudo, 3]. p.10-1 (Nota 5) 
anexada ao final do romance, uma carta ao Dr. Jaguaribe, em que Alencar claramente anuncia: "Verás realizada [neste livro] minhas idéias a respeito da literatura nacional; e achará aí poesia inteiramente brasileira [...]". ${ }^{3}$

É natural, então, que o "brasileirismo" de Iracema tenha provocado a reação de uma crítica tradicional, ligada aos valores verna-culares, que já se manifestara quando da publicação de $O$ guarani pelos ataques de Pinheiro Chagas, que indicava, no autor, o que julgava ser um de nossos defeitos nacionais: o de não saber escrever português. O ataque, entretanto, lembra Araripe Júnior, apenas desencadeara um "tufão": "[...] todo o mundo começou a achar graça em notar incorreções no autor de O Guarani" ${ }^{4} \mathrm{Um}$ tufão, portanto, que sugere virem reações de lugares mais imprevistos.

Assim, quando, em posfácio à segunda edição de Iracema, Alencar escreve um longo parecer sobre as mudanças inevitáveis na apropriação de uma língua matriz, em resposta ao colega maranhense Henriques Leal, ele apenas continuava a enfrentar a esperada resistência desta crítica tradicional. Por outro lado, entretanto, quando refutava não apenas "a reputação de inovador", mas a "pecha de escritor incorreto e descuidado", respondia também a uma nova geração crítica. ${ }^{5}$ E é sintomático, então, que Iracema tenha provocado forte polêmica em uma crítica literária que se via, ela mesma, empenhada nessa construção de uma literatura brasileira, cabendo a ela, por seu turno, eleger o corpus do que seria nossa literatura nacional.

Nessa polêmica, fica marcado o já referido estranhamento em relação à linguagem de Iracema, que, ao mesmo tempo, nem é

${ }^{3}$ ALENCAR, José de. Carta ao Dr. Jaguaribe. In: Obra completa. Vol. I. Rio de Janeiro: Aguilar, 1959. p. 307.

${ }^{4}$ ARARIPE Jr. José de Alencar: perfil literário. In: BOSI, Alfredo (org.) Araripe Júnior: teoria, crítica e história literária. São Paulo: Edusp, 1978. p. 83.

${ }^{5}$ Cf. ALENCAR, José de. Pós-escrito [à 2. edição de Iracema] In: Obra completa. Vol. I. Rio de Janeiro: Aguilar, 1959. p.309-320. 
reconhecida como brasileira, nem como literária. Araripe Júnior, correndo em defesa do escritor, elabora um conceito de interessantes sugestões:

O que não resta dúvida é que foi [José de Alencar] o primeiro que tomou, com relação à linguagem brasileira, o verdadeiro ponto de vista. Não teve, porém, a precisa decisão para aceitar a desforra completa e inelutável. O verdadeiro alvitre seria não escrever um livro sobre a língua, como prometeu, nem entrar em questões de nonada [...] A resposta única que José de Alencar tinha a dar era - que, de fato, não punha muito empenho em saber a língua portuguesa, - que o seu propósito era concorrer para corrompê-la no máximo grau $[. . .]^{6}$

Do ponto de vista da corrupção - efeito da língua brasileira sobre a portuguesa, mas também, devemos lembrar, efeito da linguagem literária sobre a língua -, de fato se torna possível perceber o estranhamento causado pela linguagem de Iracema, que, transitando entre rodapé e narrativa, narrativa e rodapé, efetua a quebra da identificação entre língua e identidade nacional, através do uso e encenação de uma língua composta, impura, não-una, estranhada e estrangeira a nós mesmos. Daí podermos dizer, então, que Iracema se constitui, ao mesmo tempo, como linguagem da ficção e como ficção da língua.

Um mesmo movimento, entretanto, percorre ainda outro tipo de notas. Pois é a esse mesmo espaço da "esquizotimia" (e não é outro o espaço das notas, que impelem o leitor constantemente a retirar os olhos da rede narrativa e a ela novamente retornar, expandindo e desdobrando a leitura) que nos impele o restante do conjunto, dedicado, por sua vez, a esclarecimentos ou observações sobre o argumento histórico utilizado na narrativa.

Por meio desse tipo de notas, distribuem-se informações sobre Martins Soares Moreno, sobre o processo de colonização e sobre nossas tribos indígenas, reforçando-se, assim, o vínculo entre a

${ }^{6}$ ARARIPE Jr. José de Alencar: perfil literário. In: BOSI, Alfredo (org.) Araripe Júnior: teoria, crítica e história literária. São Paulo: Edusp, 1978. p. 84. 
narrativa ficcional e a história nacional. Entretanto, apenas à força de certo reducionismo podemos ver, aí, na recorrência ao discurso histórico, mero artifício de legitimação da ficção pelo apelo a uma realidade externa à obra. Se, em toda medida, é indispensável reconhecer a função de criação do efeito de real, necessário a uma narrativa que, embora se autodenominando "lenda", lança mão de uma personagem e de um período históricos, a desconstrução desse efeito - já anunciada pela relação intrínseca traçada no conjunto das notas entre linguagem e argumento histórico - torna-se evidente quando chegamos à nota 56.

Ela acompanha o episódio em que Araquém, pajé da tribo tabajara, defendendo Martim contra a fúria de Irapuã, avança até o meio da cabana, ergue uma grande pedra, abrindo o chão e do antro fazendo rugir o "medonho gemido" de Tupã. Diz então a nota:

Todo esse episódio do rugido da terra é uma astúcia, como usavam os pajés e os sacerdotes dessa nação selvagem para fascinar a imaginação do povo. A cabana estava assentada sobre um rochedo, onde havia uma galeria subterrânea que comunicava com a várzea por pequena abertura; Araquém tivera o cuidado de tapar com grandes pedras as duas aberturas, para ocultar a gruta dos guerreiros. Nessa ocasião, a fenda inferior estava aberta, e o pajé o sabia; abrindo a fenda inferior, o ar encanou-se pelo antro espiral com estridor medonho [...] - O fato é, pois, natural; a aparência sim, é maravilhosa. ${ }^{7}$

Nota menos de sabor antropológico do que de reflexão teórica, o que nela se coloca em representação, na figuração do pajé, é o próprio arcabouço ficcional da narrativa, que, de um fato, "natural" ou "histórico", cria uma "aparência maravilhosa". Assim, se o narrador invade, aqui, o espaço reservado à voz autoral, o fato ficcional fica explicitamente travestido em fato natural ou histórico - e a estratégia acaba por abalar todo esse espaço de "argumentação histórica". Pois, como dissemos, também aqui assistimos a um duplo movimento.

${ }^{7}$ ALENCAR, José de. Iracema. In: . Obra completa. Vol. I. Rio de Janeiro: Aguilar, 1959. p. 258. [Nota 56] 
De início, a ficção disfarça-se em história, tomando-lhe de empréstimo a sua credibilidade, pois, como explica Charles Grivel:

A narrativa torna-se acreditável, legível, ao se desdobrar: de um lado, ficção; de outro, ficção que se preocupa em não aparecer como tal; a ficção só é aceita - como ficção, portanto! - pelo leitor se ela se recusa visivelmente a ser ficção. ${ }^{8}$

O movimento inverso e recíproco, entretanto, não deve ser esquecido: justamente porque a ficção asssume sua ficcionalidade pelo viés do disfarce histórico é que ela diz algo também sobre a própria história, sobre sua configuração intrinsecamente narrativa.

Assim, se Iracema constitui-se como que em uma espécie de projeto "complementar" de nossas fendas históricas - concordemos com as leituras tradicionais do projeto nacionalista de Alencar -, de certa forma vindo mascarar essa afasia e preenchendo, imaginariamente, suas lacunas, é justamente pelo "estridor medonho" desse artifício que a narrativa se constitui, ao mesmo tempo, na revelação dessa costura em seu avesso: a necessária consciência da História como história, ela também artifício narrativo, sempre inventada e a ponto de reinventar-se.

Dessa perspectiva, é possível reler as notas do texto e perceber esse ruído, assim como reler a própria narrativa , ainda sob a figura emblemática de Moacir - o filho de raças distintas -, mas agora em sua dupla dimensão - não mais apenas na da imagem do "filho da dor", tradicionalmente tomada como índice de uma representação pacificadora de um encontro que foi, historicamente, conflituoso, mas também na da imagem do migrante, em que Moacir se transfigura nas páginas finais do texto, e que vem desestabilizar a

${ }^{8}$ GRIVEL, Charles. Observation du roman policier. In: ARNAUD, Noël et al. Entretiens sur la paralittérature. Paris: Plon, 1970. p. 242.

${ }^{9}$ ALENCAR, José de. Iracema. In: Obra completa. Vol. I. Rio de Janeiro: Aguilar, 1959. p. 303. 
aparente harmonia narrativa. Pois é deste último lugar - o do semlugar, do predestinado a um permanente estar-em-trânsito, o da identidade não-unívoca ou sempre a se fazer - que o narrador nos pergunta: "Haveria aí a predestinação de uma raça?"9

\section{Resumo}

Este artigo se propõe a discutir a interpretação tradicional do nacionalismo literário em Iracema, de José de Alencar, a partir das relações entre o prólogo, o posfácio e as notas do autor elementos aparentemente acessórios - e a narrativa.

\section{Résumé}

Cet article se propose à discuter l'interprétation tradicionnelle du nationalisme littéraire dans Iracema, de José de Alencar. A ce propos, on étudie les relations entre des élements textuels apparemment accesoires (prologue, postface et notes) et le récit. 